\title{
Sistemas Silvipastoris como Apoio ao Desenvolvimento Rural para a Região Sudoeste do Rio Grande do Sul
}

\author{
Sônia Aparecida Guetten Ribaski('), Vitor Afonso Hoeflich(2) e Jorge Ribaski ${ }^{(3)}$
}

\begin{abstract}
(1) Faculdade Metropolitana de Curitiba, Av. Rui Barbosa 5881, Afonso Pena, CEP 83040-550, Sao José dos Pinhais-PR. E-mail: sonia@famec.com.br; (2) Universidade Federal de Paraná, Av. Lothário Meissner, 3400, CEP 80210-170, Curitiba-PR. E-mail: vitor.ufpr.gmail.com; (3) Embrapa Florestas, Estrada da Ribeira, Km 111, C.P. 319, CEP 83411-000, Colombo-PR. E-mail: ribaski@cnpf.embrapa.br
\end{abstract}

\begin{abstract}
Resumo - Foi realizada a análise da viabilidade econômica de diferentes sistemas de produção de madeira de eucalipto (Eucalyptus grandis Hill ex. Maiden) em duas propriedades rurais, no Município de Alegrete, RS. A análise econômica considerou a comparação entre um sistema tradicional de pecuária da região e dois sistemas alternativos de conversão da área de pecuária para plantios homogêneos de eucalipto em duas densidades com 2.222 e 1.111 árvores.ha ${ }^{-1} \mathrm{e}$ dois sistemas silvipastoris: com 1.000 e 500 árvores.ha ${ }^{-1}$. A análise dos resultados foi realizada a partir da determinação da Taxa Interna de Retorno (TIR) e da sua comparação com a Taxa Mínima de Atratividade (TMA). As alternativas com e sem o valor da terra foram avaliadas considerando uma variação do preço (aumento e diminuição de 5\%) e do volume da madeira (aumento e diminuição de $10 \%$ ). Considerando o valor da terra, todas as alternativas analisadas apresentaram TIR inferior a TMA $(3,72 \%)$. A análise de sensibilidade mostrou que, havendo aumento do preço e do volume de madeira, a maioria das alternativas com desbaste apresentou TIR superior a TMA, exceto a alternativa do sistema silvipastoril com 500 árvores.ha ${ }^{-1}$. Dessa forma, a implantação do componente florestal na propriedade rural, quando não se considerou o valor da terra, apresentou-se economicamente viável para o produtor rural.
\end{abstract}

Termos para indexação: Pecuária extensiva, produção florestal, sistema silvipastoril, avaliação econômica, Eucalyptus grandis.

\section{Silvopastoral Systems as a Support for Rural Development in the Southwest Region of Rio Grande do Sul State, Brazil}

\begin{abstract}
An economic viability analysis was performed for different eucalypt wood production systems (Eucalyptus grandis Hill ex. Maiden) in two rural properties located in Alegrete County, RS. The traditional pasture system was compared with two other alternative systems, one of them represented by a pasture land converted to homogeneous eucalypt plantation by using two plant densities $\left(2,222\right.$ and 1,111 trees.ha $\left.{ }^{-1}\right)$ and the other represented by a silvopastoral system containing 1,000 and 500 trees.ha ${ }^{-1}$. The results were analyzed by determining the Internal Retuurn Rate (IRR) and comparing it to the Minimum Attractive Rate (MAR). The alternatives with and without land value were evaluated taking into account the wood price variation (gain and lost of 5\%) and the wood yield (gain and lost of $10 \%$ ). Considering the land value, all alternatives showed that the IRR was lower than the MAR (3.72\%). The sensibility analysis showed that when price and yield of the wood had their values increased, for the majority of alternatives considering the practice of thinning, the IRR was higher than the MAR, except to silvopastoral system containing 500 trees.ha $^{-1}$. The conclusion was that, the forest component implementation is economically viable for the land owner, except by the fact that it is necessary to disregard the land value in this approach.
\end{abstract}

Index terms: Extensive cattle raising, forestry production, silvopastoral system, economic evaluation, Eucalyptus grandis.

\section{Introdução}

A discussão sobre desenvolvimento sustentável na metade sul do Rio Grande do Sul, em particular no Bioma Pampa, representa objeto de vários estudos em relação ao modelo de desenvolvimento existente na região e seus efeitos, no que tange à população e ao meio ambiente. Existe consenso nesses estudos sobre a necessidade de diversificação da matriz produtiva, visando melhorar a rentabilidade do sistema produtivo. 
A cadeia produtiva da pecuária é uma das mais tradicionais do estado, com grande importância econômica e social e poder de integração regional. Entretanto, o retorno econômico das propriedades que desenvolvem a pecuária de corte tem sido prejudicado devido ao aumento dos preços dos insumos, além da queda do valor do boi vivo, pago ao produtor. Boa parte das propriedades depende exclusivamente de recursos forrageiros naturais para a alimentação do rebanho, e os utilizam de forma extensiva, proporcionando baixa produção por unidade de área, o que, muitas vezes, pode inviabilizar pequenas e médias propriedades (SILVA, 2006).

A região sudoeste do estado, em particular, é uma área considerada de alta vulnerabilidade sócioeconômica, em razão de possuir extensas formações arenosas que vêm sofrendo alterações dos padrões de vegetação devido à diminuição da cobertura vegetal e, consequentemente, o aumento da erosão desses solos, resultando em degradação do ecossistema regional, denominado Bioma Pampa.

Esse processo de degradação ambiental tem refletido negativamente sobre as condições socioeconômicas, induzindo à queda da qualidade de vida do homem do campo. Atualmente, pode-se perceber fortes tendências para mudanças significativas na forma dos diferentes sistemas de utilização da terra, em que os aspectos relativos à sustentabilidade ambiental e à criação de novas alternativas socioeconômicas vêm assumindo importância cada vez maior para os produtores dessa região.

Desde o ano 2000, novos e importantes investimentos são feitos na metade sul por grandes indústrias na área de celulose e papel. Esses investimentos compreendem, também, a estruturação de um setor florestal integrado em cadeias produtivas e espalhado por vários municípios da região (ASSOCIAÇÃO GAÚCHA DE EMPRESAS FLORESTAIS, 2005).

Desta forma, delineia-se um cenário para a metade sul com uma estrutura econômica mais diversificada e dinâmica, com o crescimento da lavoura de grãos integrada à pecuária de corte mais produtiva nas terras com maior potencialidade de uso, e com a constituição de um setor florestal mais forte associado a cadeias agroindustriais nas áreas com menor aptidão para agricultura (ILHA et al., 2006).

Visualiza-se o emprego de sistemas silvipastoris (SSPs) como uma importante estratégia de uso sustentado da terra, principalmente nas áreas potencialmente sujeitas à degradação ambiental e, também, como uma nova fonte de agregação de valor econômico à propriedade rural através da exploração madeireira (RIBASKI et al., 2001).

Diversos resultados de pesquisa mostram as vantagens dos SSPs em relação aos sistemas tradicionais, principalmente por atenderem as premissas de desenvolvimento econômico e social atreladas às questões de proteção e aumento da sustentabilidade ambiental dos sistemas produtivos (RIBASKI et al., 2001; 2005). Por outro lado, estes sistemas apresentam uma maior complexidade que os sistemas tradicionais e demandam informações técnicas pormenorizadas de cada um dos seus componentes para que se possa definir um planejamento estratégico adequado, visando lograr o êxito desejado.

Dentro desse contexto, percebe-se a necessidade da ampliação da base científica para fornecer subsídios técnicos, principalmente, para se determinar a viabilidade econômica desses sistemas. Na região de estudo, a adoção dos SSPs ainda é incipiente e poucas iniciativas de pesquisa contemplam avaliações econômicas desses sistemas integrados de produção. Nessa perspectiva, esse trabalho foi desenvolvido, tendo como objetivo avaliar economicamente a utilização de SSPs como apoio a ação de desenvolvimento rural para a região sudoeste do Rio Grande do Sul.

\section{Material e Métodos}

\section{Caracterização da Unidade Padrão}

A unidade de produção denominada "Fazenda Modelo" foi concebida a partir de dados oriundos de um projeto de pesquisa desenvolvido na região em estudo pela Embrapa Florestas, em parceria com a Embrapa Clima Temperado, Embrapa Pecuária Sul e outras instituições de pesquisa, ensino e extensão. O projeto foi implantado em 2002, no Município de Alegrete, RS, em duas propriedades rurais previamente selecionadas pelas instituições parceiras, com base nas características socioeconômicas e edáficas representativas da região.

O tamanho da "Fazenda Modelo" foi definido em 300 ha, coincidindo com o tamanho da área limite para que fosse considerada como pecuária familiar, que representa a maioria dos produtores da pecuária de corte (PILLAR et al., 2006). A área 
efetiva para uso produtivo compreendeu 175 ha, após desconsiderar as áreas de produção restritas, como Área de Preservação Permanente e Reserva Legal, e área de ocupação com infra-estrutura da propriedade - sede da fazenda, galpão, mangueira e outras benfeitorias.

\section{Detalhamentos das alternativas para análise econômica comparativa}

Foram delineadas cinco alternativas, combinando as formas de uso do solo da unidade padrão fundiária, à "Fazenda Modelo", no sentido de analisar a viabilidade econômica das atividades pecuária e plantios florestais homogêneos e SSPs com Eucalyptus grandis, na região em estudo (Tabela 1).

\section{Alternativa 1: Pecuária tradicional}

Refere-se ao emprego do sistema tradicional de pecuária de corte extensiva na área produtiva, em regime de recria e terminação de novilhos, para o qual são necessários, em média, dois hectares por cabeça (CASTILHOS et al., 2003).

O peso médio para compra dos novilhos, com um ano de idade, foi de $230 \mathrm{~kg}$ e, para venda, animais de três anos, de $350 \mathrm{~kg}$. Para efeito de cálculo, a média de produtividade foi considerada em torno de $60 \mathrm{~kg}$ de peso vivo (PV).ha ${ }^{-1}$.ano ${ }^{-1}$ (PILLAR et al., 2006) e valor da compra e da venda do gado $(\mathrm{R} \$ 2,00 / \mathrm{kg})$.

No primeiro ano da pesquisa, o gado com três anos de idade foi comercializado e 45 novas cabeças com um ano foram adquiridas. Desta forma, o produtor manteve seu plantel estável, com o número máximo de 90 cabeças, como se propõe na criação extensiva em campo nativo, comercializando anualmente 45 cabeças.

Tabela 1. Espaçamentos e densidade inicial de plantio para o Eucalyptus grandis em cada alternativa analisada.

\begin{tabular}{clcc}
\hline Alternativas & \multicolumn{1}{c}{ Tratamentos } & Espaçamentos (m) & $\begin{array}{c}\text { Densidade Inicial } \\
\left(\text { árvores.ha- }^{-1}\right)\end{array}$ \\
\hline 1 & Criação extensiva de gado & - & - \\
2 & Plantio homogêneo & $3 \times 1,5$ & 2.222 \\
3 & Plantio homogêneo & $3 \times 3$ & 1.111 \\
4 & Sistema silvipastoril 1 & $(3 \times 1,5) \times 14$ & 1.000 \\
5 & Sistema silvipastoril 2 & $(3 \times 1,5) \times 34$ & 500 \\
\hline
\end{tabular}

Alternativas 2 e 3: Pecuária com conversão gradativa para plantio florestal homogêneo

Estas duas alternativas compreendem a conversão gradativa da área de pastagem em plantio florestal de eucalipto, com densidades de 2.222 e 1.111 árvores. $\mathrm{ha}^{-1}$, respectivamente. A área produtiva, de 175 ha, foi dividida em sete módulos de 25 ha cada, sendo que, anualmente converte-se um módulo, obtendo-se ao sétimo ano a conversão total da área produtiva da propriedade. Consequentemente, o número de cabeças de gado também foi sendo reduzido gradativamente, cedendo lugar para o plantio florestal (Figura 1).
Alternativa 4: Sistema silvipastoril com 1.000 árvores.ha ${ }^{-1}$

Consiste no emprego de SSP com eucalipto plantado em linhas triplas, com espaçamento de $3 \mathrm{~m} \times 1,5 \mathrm{~m}$, totalizando 1.000 árvores.ha ${ }^{-1}$ e corredor de pastagem natural entre os conjuntos de linhas de $14 \mathrm{~m}$, o que corresponde a $45 \%$ da área para plantio florestal e 55\% para pastagem (Figura 2). Tem-se, portanto, por módulo de 25 ha, 11,25 ha destinados à produção florestal e 13,75 ha para criação extensiva de gado.

Assim, este sistema prevê a inserção gradativa de plantio florestal ao longo de sete anos e, de forma inversa, a redução do pastoreio. Portanto, o gado é inicialmente a atividade que ocupa a maior parte do terreno (90 cabeças), sendo gradativamente reduzido à quantidade de 49 cabeças para ocupação final de $55 \%$ da área, ou seja, 96 ha de pastagem. 


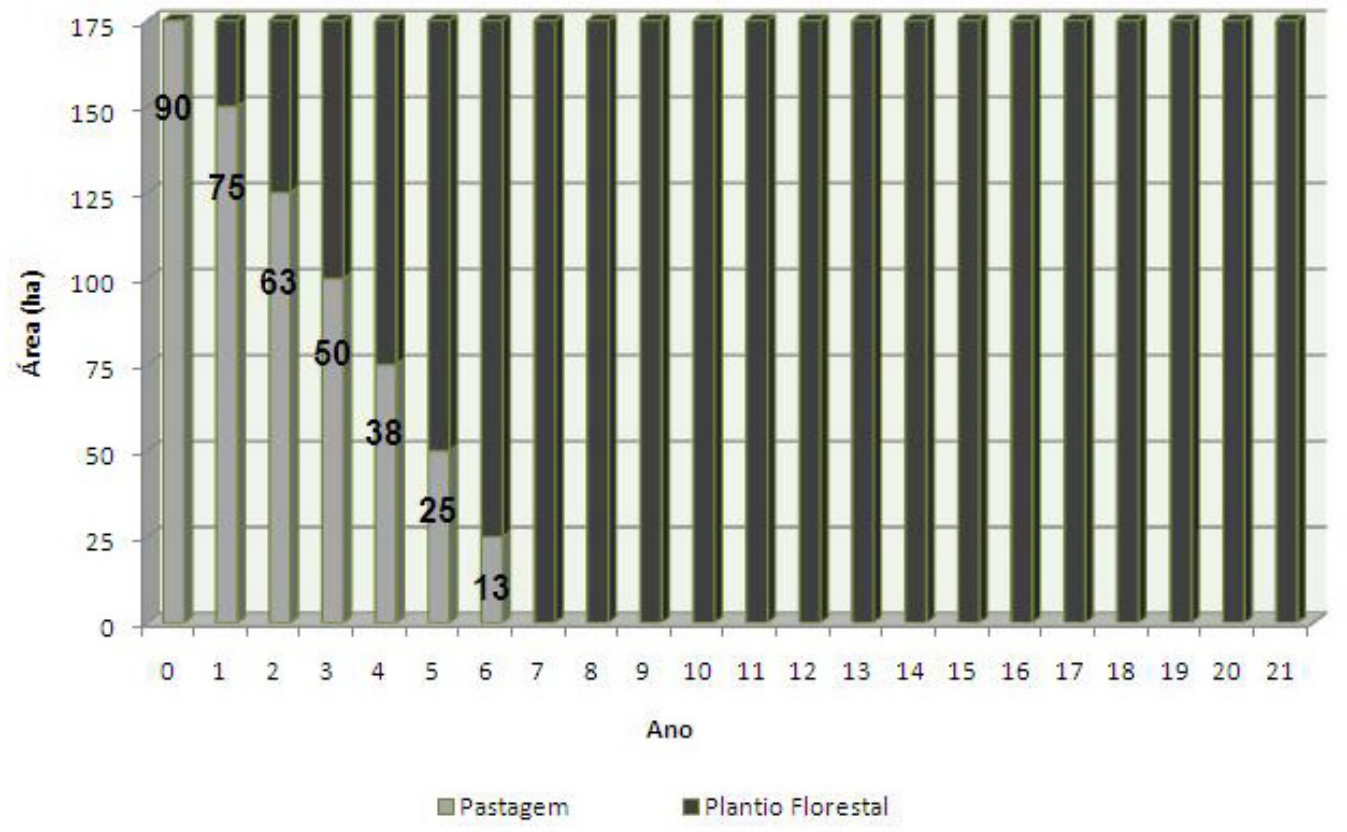

Figura 1. Distribuição anual da conversão gradativa da pecuária extensiva para plantio florestal homogêneo e respectiva quantidade de cabeças de gado

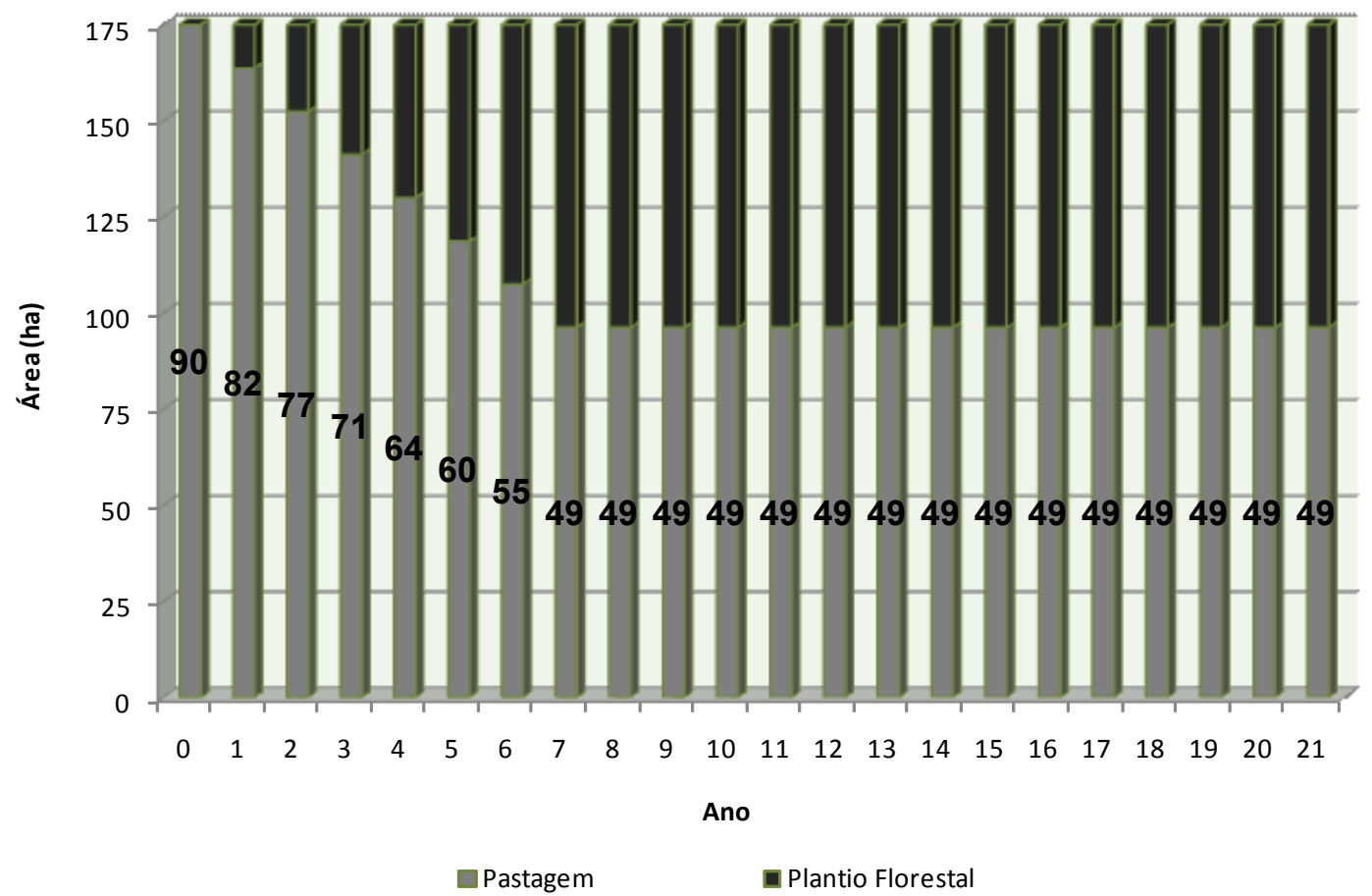

Figura 2. Distribuição anual da conversão da área com pecuária extensiva para sistema silvipastoril com 1.000 árvores.ha $^{-1}$ e número de cabeças de gado por ano. 
Alternativa 5: Sistema silvipastoril com 500 árvores. ha ${ }^{-1}$

A alternativa 5 consiste no emprego de SSP com eucalipto plantado em linhas triplas, com espaçamento de $3 \mathrm{~m}$ x 1,5 m, totalizando 500 árvores. $\mathrm{ha}^{-1}$ e corredor de pastagem natural entre os conjuntos de linhas de 34 $\mathrm{m}$, o que corresponde a $22,5 \%$ de plantio e $77,5 \%$ de pastagem. Tem-se, portanto, por módulo de 25 ha, 5,6 ha destinados à produção florestal e 19,4 ha para criação extensiva de gado, correspondendo à quantidade de 70 cabeças para ocupação final de 135 ha de pastagem (Figura 3).

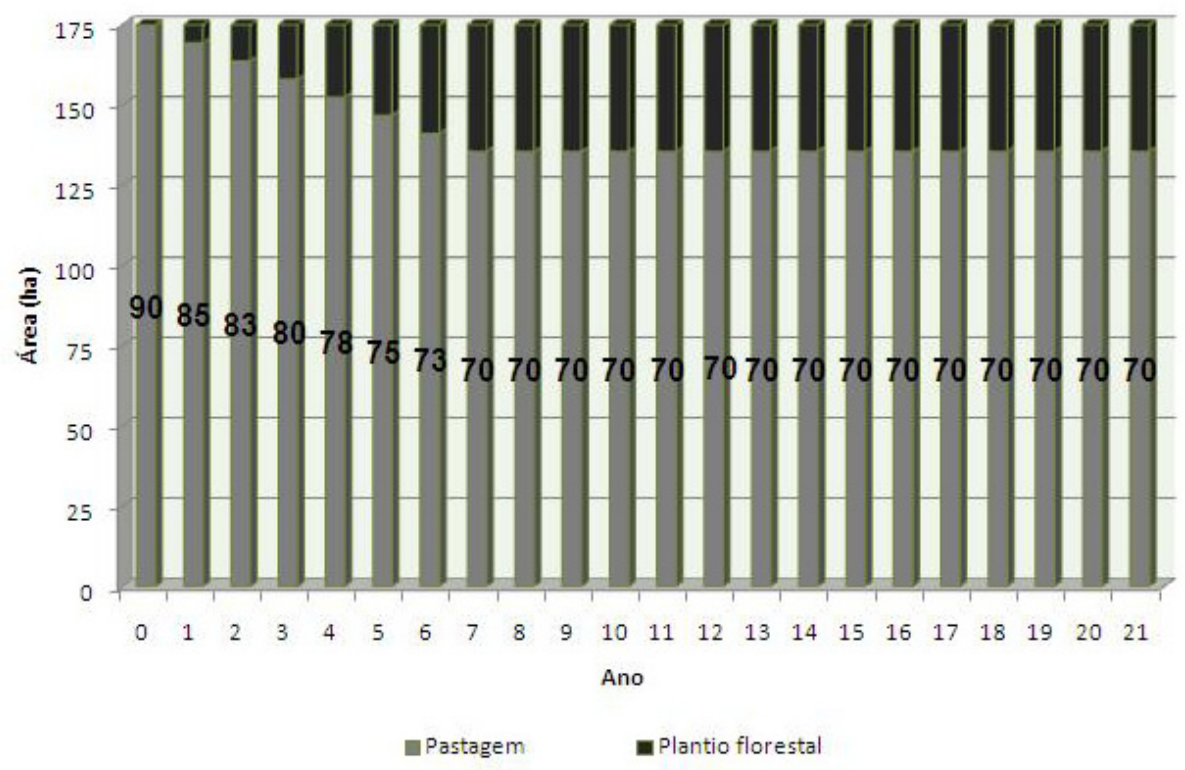

Figura 3. Distribuição anual da conversão da área com pecuária extensiva para sistema silvipastoril com 500 árvores.ha ${ }^{-1}$ e número de cabeças de gado por ano.

\section{Produção Florestal}

O ciclo de produção definido neste estudo compreende 21 anos, realizando-se o primeiro corte aos sete anos e conduzindo o plantio em regime de talhadia simples até os 14 anos (STAPE, 1997; RODRIGUEZ, 1999), ocasião em que ocorre o segundo corte. A cada ano é realizado um novo plantio de 25 ha, por um período contínuo de sete anos, sendo que a partir do sétimo ano cada módulo sofre um corte raso e a rebrota é conduzida até o segundo corte. O último plantio realizado aos sete anos tem a sua rebrota conduzida e cortada aos 21 anos encerrando o ciclo.

Visando aumentar o percentual de madeira para serraria (maior valor agregado), além do sistema descrito anteriormente, adotou-se também um manejo diferenciado, que consistiu do desbaste seletivo de $70 \%$ das árvores aos 7 anos, deixando os outros $30 \%$ de árvores remanescentes de melhor qualidade para serem cortadas aos 14 anos de idade junto com o corte da segunda rotação.
A prognose da produção de madeira para os SSPs e plantio homogêneo até o final do ciclo foi simulada pelo software SisEucalipto (OLIVEIRA, 2002; OLIVEIRA et al., 2006), e expressa em $\mathrm{m}^{3} \cdot \mathrm{ha}^{-1}$. O decréscimo volumétrico estabelecido para a prognose da segunda rotação para este trabalho foi de $25 \%$ a menos de volume, para fins de simulação (BERGER, 1979; SILVEIRA; HIGASHI, 2001). O valor da madeira em pé para venda para celulose foi considerado $\mathrm{R} \$ 20,00 \mathrm{o} \mathrm{m}^{3}$ e para serraria $R \$ 50,00 \mathrm{o} \mathrm{m}^{3}$. A matéria-prima para celulose englobou o sortimento energia (SisEucalipto) e para madeira de serraria foi considerado o somatório dos sortimentos laminação e serraria.

\section{Critérios de avaliação econômica}

A análise econômica se fundamenta, basicamente, na comparação das atividades produtivas dos arranjos alternativos. Esta comparação foi feita por meio de critérios que consideram a atualização da variação sofrida pelo capital, em função de sua distribuição no horizonte de 21 anos. 
No fluxo de caixa foram incluídos os investimentos da propriedade, os custos de implantação e manutenção do eucalipto, custos de insumos, de mão-de-obra e de manutenção do gado nos diferentes sistemas alternativos. Também foram incluídas as receitas resultantes da comercialização dos produtos obtidos durante todo o ciclo, pela comercialização do gado e da madeira.

Para realizar o estudo da análise da viabilidade dos arranjos, foi considerada uma Taxa Mínima de Atratividade (TMA) equivalente à média do rendimento da poupança real (poupança nominal menos inflação). Para o período de 1996-2006, a poupança nominal média foi de $10,57 \%$ enquanto a inflação, expressa pelo INPC, teve variação média de $6,85 \%$, o que resulta em uma poupança real $3,72 \%$, aplicada como TMA para avaliação das alternativas.

Quanto mais próxima a TIR da TMA (ainda que maior a TIR), significa que o risco do projeto aumenta. Se a TIR for menor que a taxa de desconto, significa que o projeto em análise, se implementado, renderá menos que se investido em outro projeto aplicado à taxa de desconto. Ou seja, a escolha de um investimento deve, normalmente, recair sobre aquele que tiver a maior TIR.

\section{Análise de sensibilidade}

Foi realizada uma análise de sensibilidade da TIR às variações nos índices de produtividade e nos preços de madeira, para estabelecer a influência destes fatores na viabilidade econômica das alternativas. Para análise de sensibilidade neste trabalho, simulou-se a variação do aumento e diminuição de $5 \%$ no preço da madeira (celulose e serraria) e do aumento e diminuição de $10 \%$ na produtividade da madeira.

Contando com a possibilidade de o produtor já possuir a terra, o que implicaria somente a conversão da pecuária extensiva para plantio florestal homogêneo ou SSP, também foram realizadas análises de situações que não consideraram os valores relativos à aquisição da terra. Em todas as alternativas, contudo, foram considerados todos os custos e investimentos requeridos pela atividade florestal e pecuária.

\section{Resultados e discussões}

\section{Prognose de crescimento do eucalipto nas diferentes alternativas analisadas}

A adoção do manejo com desbaste, em todas as alternativas, promoveu um maior incremento em produtividade total. Este aumento é esperado, uma vez que o desbaste de $70 \%$ das árvores no sétimo ano promove a abertura do povoamento e consequente redução da competição por luz, água e nutrientes por parte das árvores remanescentes. O desenvolvimento destas árvores produz fustes com maiores dimensões e madeira de maior qualidade, própria para a utilização em serraria, obtendo-se um maior valor pela matéria-prima produzida.

A produtividade nas diferentes alternativas para o período de produção de 14 anos, correspondendo a dois ciclos, pode ser visualizada na Figura 4.

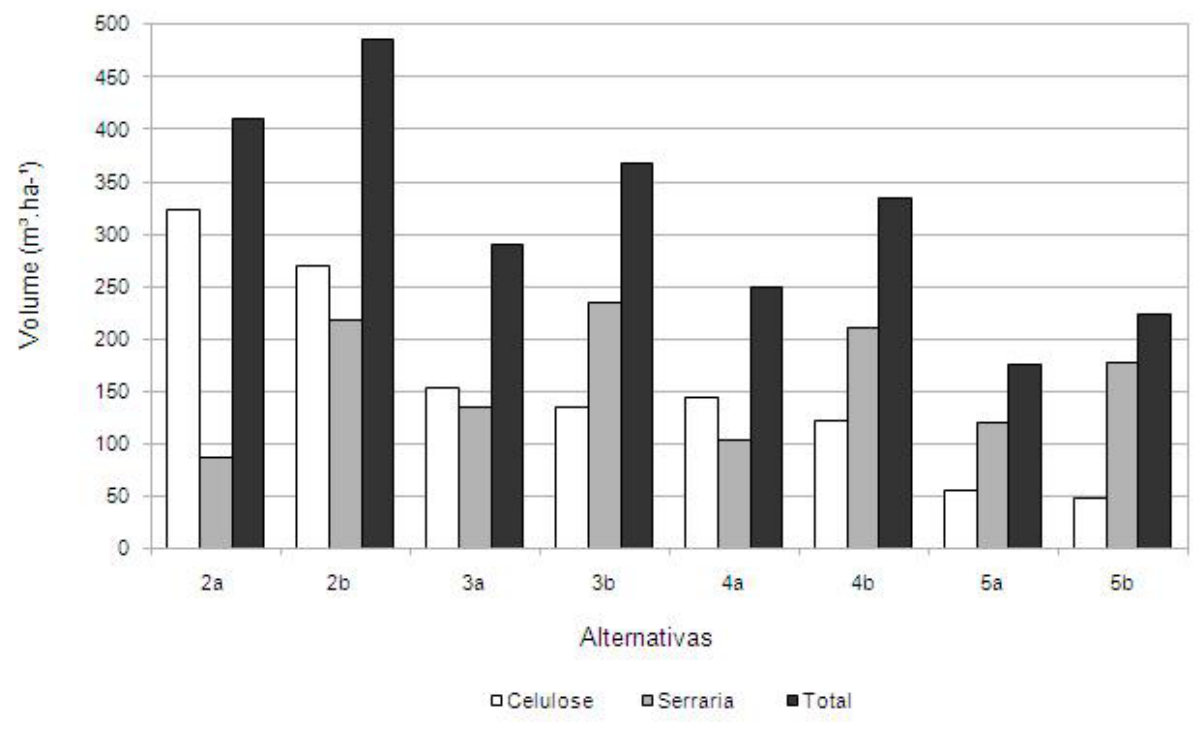

Figura 4. Produção total de madeira para celulose eserraria nas diferentes alternativas, com e sem desbaste, em um ciclo de 14 anos. a - manejo sem desbaste; $b$ - manejo com desbaste seletivo de $70 \%$ das árvores no sétimo ano. 
A constatação é de que, em termos de produtividade total, as alternativas com desbaste produzem maior volume de madeira (Figura 4). A adoção do manejo com desbaste, em todas as alternativas, promoveu um maior incremento em produtividade total: $18,6 \%$, $27,26 \%, 33,96 \%$ e $27,84 \%$ para as alternativas $2,3,4$ e 5 , respectivamente. Este aumento é ainda mais perceptível quando se considera o somatório dos sortimentos serraria e laminação, constatando-se incremento médio de $93,5 \%$.

\section{Análises comparativas das alternativas}

$\mathrm{Na}$ Tabela 2 estão indicados os resultados dos cálculos da TIR que foram obtidos a partir das diferentes alternativas testadas, extraídos dos fluxos de caixa, ao longo de todo o período de 21 anos, onde foram considerados todos os investimentos, inclusive o valor da terra.

Um projeto é considerado viável economicamente se apresentar TIR > TMA. Desta forma, analisando a Tabela 2 , é possível verificar que, frente à TMA de $3,72 \%$ ao ano, a TIR mostra que tanto os plantios homogêneos quanto os SSPs considerando o valor da terra apresentam TIR abaixo da TMA, sendo a TMA definida como o valor médio da poupança real já descontada a inflação pela série histórica no período de 1996 a 2006.

Tabela 2. Comparação entre as taxas internas de retorno (TIR) obtidas na análise econômica das diferentes alternativas avaliadas com e sem desbaste.

\begin{tabular}{|c|c|c|}
\hline Alternativas & $\begin{array}{c}\text { TIR (\%) } \\
\text { Sem desbaste }\end{array}$ & $\begin{array}{c}\text { TIR (\%) } \\
\text { Com desbaste }\end{array}$ \\
\hline $\begin{array}{l}\text { Alternativa 1: pecuária } \\
\text { extensiva tradicional }\end{array}$ & $<0$ & $<0$ \\
\hline $\begin{array}{l}\text { Alternativa } 2 \text { : plantio } \\
\text { homogêneo }(3 \mathrm{mx} 1,5 \mathrm{~m}) \\
2.222 \text { árvores. } \mathrm{ha}^{-1}\end{array}$ & 1,04 & 3,12 \\
\hline $\begin{array}{l}\text { Alternativa 3: plantio } \\
\text { homogêneo }(3 \mathrm{~m} \mathrm{x} 3 \mathrm{~m}) \\
1.111 \text { árvores.ha }{ }^{-1}\end{array}$ & 1,33 & 2,68 \\
\hline $\begin{array}{l}\text { Alternativa } 4: \\
\text { sistema silvipastoril } \\
1.000 \text { árvores. } \text { ha }^{-1}\end{array}$ & $<0$ & 2,08 \\
\hline $\begin{array}{l}\text { Alternativa } 5 \text { : } \\
\text { sistema silvipastoril } \\
500 \text { árvores. } \text { ha }^{-1}\end{array}$ & $<0$ & 0,62 \\
\hline
\end{tabular}

No que tange à pecuária extensiva (Alternativa 1), os lançamentos demonstraram uma receita líquida negativa. Neste contexto, a TIR não pôde ser determinada. A análise deste trabalho indica que a pecuária extensiva não se traduz em retorno econômico ao produtor. A receita total para esta alternativa é insuficiente para cobrir os custos de produção.

O uso tradicional da terra com a pecuária extensiva em campos naturais (alternativa 1) apresentou receita líquida negativa em todo o período analisado, demonstrando sua inviabilidade econômica. Apesar de anualmente o gado ser comercializado, os custos de produção e a manutenção da infraestrutura superam as receitas obtidas.

Embora as outras alternativas tenham apresentado TIR positivas, todas as taxas foram inferiores ao TMA, demonstrando a não-viabilidade do investimento nas condições consideradas.

Para o produtor rural, nas condições avaliadas, o plantio florestal homogêneo com desbaste apresenta-se como alternativa econômica mais próxima da TMA para melhoria da renda, mas ainda sim inferior a ela. O plantio de florestas requer investimentos iniciais relativamente altos, mas compensados pela produtividade e preço final da madeira. É um investimento de médio a longo prazo, com retorno garantido pelo mercado florestal crescente no Brasil e o aumento do uso da madeira. Porém, os investimentos da terra, das benfeitorias e o prejuízo causado pela pecuária contribuíram para o resultado negativo nos anos iniciais e ainda nos resultados negativos finais de algumas das alternativas avaliadas.

\section{Análise de sensibilidade}

Os resultados da análise de sensibilidade para as alternativas e cenários avaliados estão descritos na Tabela 3, considerando a variação de $5 \%$ no preço da madeira (celulose e serraria) e 10\% na produtividade da madeira, analisando as alternativas com e sem o valor de aquisição da terra. 
Tabela 3. Análise de sensibilidade para as alternativas avaliadas com e sem desbaste e com e sem o valor da terra considerando também variações no preço e produtividade da madeira.

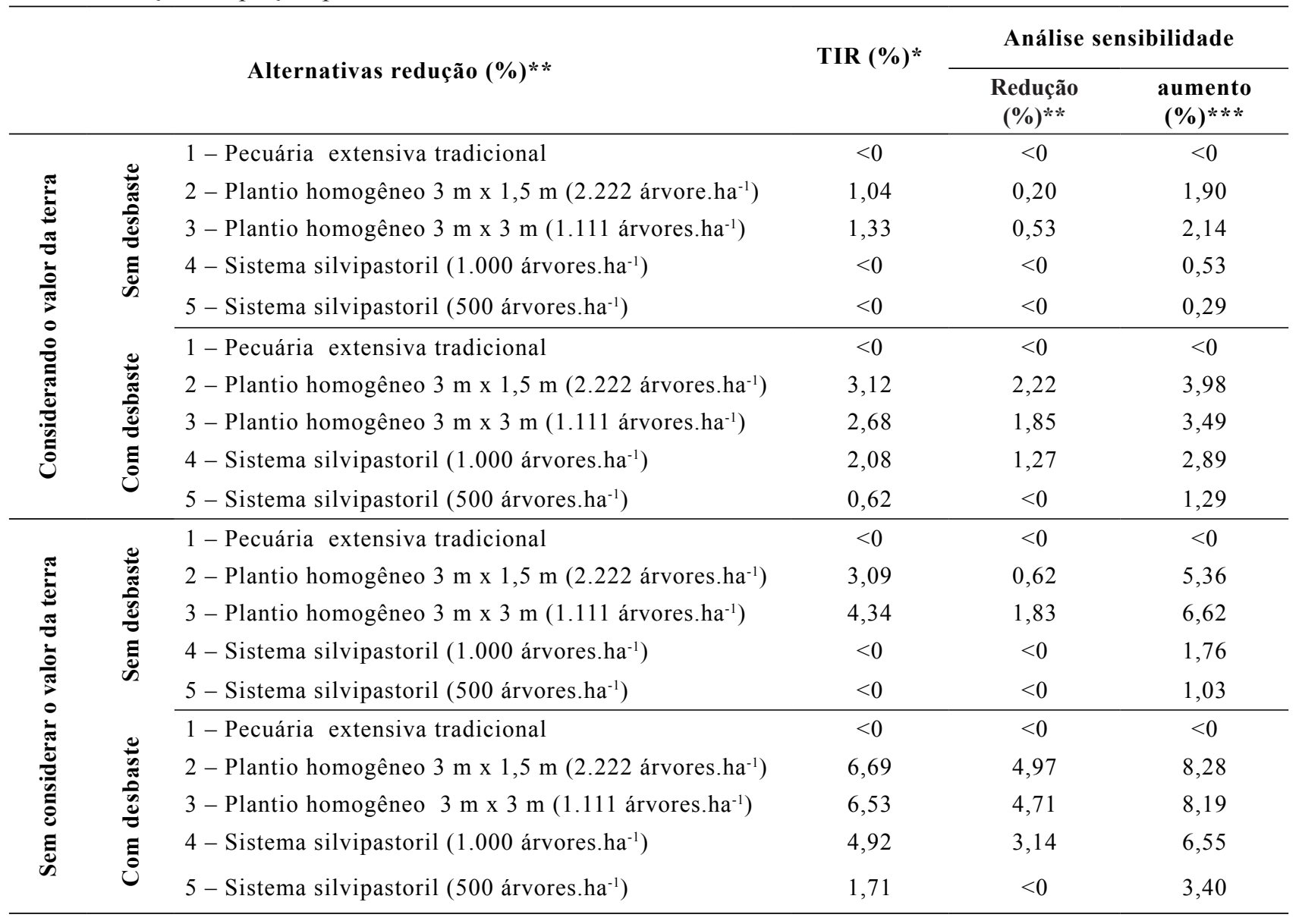

* TIR considerando as condições analisadas com e sem considerar o valor da terra; ** TIR considerando uma redução de $5 \%$ no valor da madeira e $10 \%$ na produção de madeira; *** TIR considerando um aumento de $5 \%$ no valor da madeira e $10 \%$ na produção de madeira.

Análise do modelo de pecuária extensiva tradicional

A alternativa 1 não apresentou alteração da TIR (Tabela 3), porque ela não contempla a sua conversão gradativa para plantio florestal ou sistema silvipastoril. Dessa forma, a pecuária extensiva praticada nos campos naturais do sudoeste do Rio Grande do Sul, nas condições analisadas, constituise numa opção não-rentável economicamente para o produtor rural. Resultados semelhantes também foram encontrados no Diagnóstico de Sistemas de Produção de Bovinocultura de Corte do Estado do Rio Grande do Sul (MIGUEL et al., 2007), indicando que, na maioria das vezes, os resultados agroeconômicos apresentam indicadores de eficiência econômica baixa ou negativa.
De acordo com esse mesmo diagnóstico, $26,5 \%$ dos produtores praticam a atividade por tradição, 25,4\% por satisfação e $14,4 \%$ por considerarem ser esta uma atividade segura. Apenas $8,7 \%$ possuem uma visão empresarial da atividade, visando à obtenção de lucro. Outras conclusões do diagnóstico apontam que os pecuaristas possuem baixa qualificação técnica e pouco capital imobilizado, encontrandose em situação de endividamento e em dificuldades com a sucessão e continuidade da atividade pecuária.

Entretanto, diversos resultados de pesquisa mostram que o baixo rendimento dos animais obtido sobre o campo nativo $\left(60 \mathrm{~kg}\right.$ de $\mathrm{PV} \cdot \mathrm{ha}^{-1}$.ano $\left.{ }^{-1}\right)$ pode ser melhorado com simples procedimentos que não demandam aumentos consideráveis nos custos de produção (NABINGER, 2006; PILLAR et al., 2006). 
Pillar et al. (2006), por exemplo, trabalhando com sistemas de recria e terminação de bovinos, constataram que somente com o ajuste correto de carga animal (custo quase zero) podem ser conseguidos ganhos de peso significativos na ordem de $230 \mathrm{~kg}$ de $\mathrm{PV} \cdot \mathrm{ha}^{-1}$. nno $^{-1}$. Adequando a carga animal com a capacidade de suporte da pastagem, Nabinger (2006) relata que os valores podem chegar entre 150 e $170 \mathrm{~kg} \cdot \mathrm{ha}^{-1}$.ano ${ }^{-1}$ de peso vivo, com oferta de forragem fixa ao longo de ano e até valores próximos a $250 \mathrm{~kg} \cdot \mathrm{ha}^{-1}$. ano $^{-1}$, alternando a oferta de forragem na primavera em relação ao restante do ano.

O diferimento da pastagem nativa, ou seja, a retirada dos animais de potreiro por um determinado tempo, também é uma ferramenta de manejo barata, que proporciona reserva de forragem para ser utilizada em períodos críticos do ano (CASTILHOS et al., 2003; NABINGER, 2006).

Como ressalta Silva (2006), a atividade de pecuária de corte, com as características atuais dos sistemas de produção, provavelmente não se encaixa nos conceitos da sustentabilidade. Boa parte das propriedades depende exclusivamente dos recursos forrageiros naturais para a alimentação do rebanho e o utilizam de forma extensiva, proporcionando baixa produção por unidade de área, o que inviabiliza propriedades médias e pequenas. Este sistema produtivo extensivo não aporta renda substancial ao produtor, não incrementa o comércio nas cidades e não contribui para o aumento da oferta de postos de trabalho na região.

Análise das alternativas com o componente florestal, considerando o valor da terra com e sem desbaste

Nas alternativas em que foram computados também o acréscimo de $5 \%$ no preço da madeira e $10 \%$ de aumento na produtividade nas alternativas com desbaste (Tabela 3), ocorreu um acréscimo nos percentuais da TIR. Entretanto, esses acréscimos, em geral, não foram suficientes para superar a TMA. A alternativa 2, porém, apresentou TIR de 3,98\%, superior à TMA.

$\mathrm{Na}$ análise das alternativas com redução de $5 \%$ no preço da madeira e $10 \%$ na produtividade, para todas as alternativas, a TIR foi inferior à TMA. Apesar disso, pode-se observar também que com exceção da 5 , todas as alternativas com desbaste apresentaram TIR positiva, sendo superior às alternativas sem desbaste.
Análise das alternativas com o componente florestal, sem considerar o valor da terra com e sem desbaste

Considerando o acréscimo de $5 \%$ no preço da madeira e $10 \%$ de aumento na produtividade, para as alternativas com desbaste, observa-se que todas as TIRs apresentaram valores positivos. As alternativas 2, $3 \mathrm{e}$ 4 foram superiores à TMA. Verifica-se, assim, que o produtor pode optar por plantios homogêneos ou SSP com 1.000 árvores.ha ${ }^{-1}$ (alternativa 4).

$\mathrm{Na}$ análise das alternativas sem desbaste, as que alcançaram TIRs acima da TMA foram a 2 e 3 (plantios florestais homogêneos), sendo que as alternativas 4 e 5 não apresentaram o resultado esperado.

Analisando as alternativas com redução de $5 \%$ no preço da madeira e $10 \%$ na produtividade, considerando o desbaste, somente as alternativas 2 e 3 (plantios florestais homogêneos) apresentam TIR superior à TMA, mesmo com a redução do preço e do volume de madeira, enquanto nas alternativas sem desbaste, todas apresentaram TIR abaixo da TMA.

De maneira geral, as alternativas de comercialização da madeira, priorizando matéria-prima para serraria, por meio de desbastes, apresentaram TIRs superiores às que foram manejadas por meio de talhadia simples, mostrando-se assim mais lucrativas.

Comportamento anual acumulado da receita líquida até $o 21^{\circ}$ ano das alternativas com TIR superior à TMA (3,72\%)

Comparando as alternativas que envolvem plantios florestais homogêneos e SSP com TIR superior à TMA, em relação à pecuária extensiva (alternativa 1 ), foi observado que somente a partir do $17^{\circ}$ ano na conversão para os plantios florestais homogêneos e a partir do $18^{\circ}$ ano para o SSP, a receita líquida acumulada foi positiva. A pecuária, por gerar prejuízos neste caso, colaborou para que a receita líquida acumulada não ocorresse antes da colheita das árvores.

Até o $7^{\circ}$ ano, os custos da atividade florestal foram superiores aos da pecuária, tendo em vista que a atividade florestal ainda não gerou receita e a pecuária gerou prejuízos. A partir do oitavo ano, quando tem início a comercialização da madeira, ocorreu um incremento da receita, não o suficiente para superar a receita líquida negativa acumulada. 
Importante salientar que a madeira comercializada no $8^{\circ}$ ano corresponde somente à produção do primeiro plantio, enquanto a receita líquida acumulada equivale às despesas da pecuária e dos demais plantios anuais já realizados.

A alternativa 3, sem desbaste, apresentou receita acumulada superior à alternativa 1 (pecuária extensiva) a partir do $10^{\circ}$ ano. Da mesma forma, as alternativas 2, 3 e 4, com desbaste, apresentaram receita líquida acumulada superior à alternativa 1 no $15^{\circ}$ ano e, respectivamente, nos $14^{\circ}$ ano e $15^{\circ}$ ano.

A alternativa 2, com desbaste, apresentou maior rentabilidade ao final do período avaliado devido ao maior volume de madeira comercializado.

A alternativa 4, SSP com desbaste, mesmo com o efeito negativo da pecuária e apresentando resultado acumulado positivo somente a partir do $18^{\circ}$ ano, superou o resultado econômico do plantio florestal homogêneo sem desbaste, apresentando uma rentabilidade superior à TMA e mantendo a atividade tradicional da pecuária na região.

A Figura 5 contempla os resultados obtidos nos fluxos de caixa anuais acumulados das alternativas que obtiveram TIR superior à TMA utilizada neste trabalho.

Caso a pecuária gerasse lucro, ou, pelo menos cobrisse suas despesas, a rentabilidade dos sistemas silvipastoris seria ainda maior. Além disso, não foram considerados os efeitos benéficos do componente arbóreo para a pecuária no que tange ao sombreamento, amenização de frio e calor excessivos e melhoria da qualidade do solo.

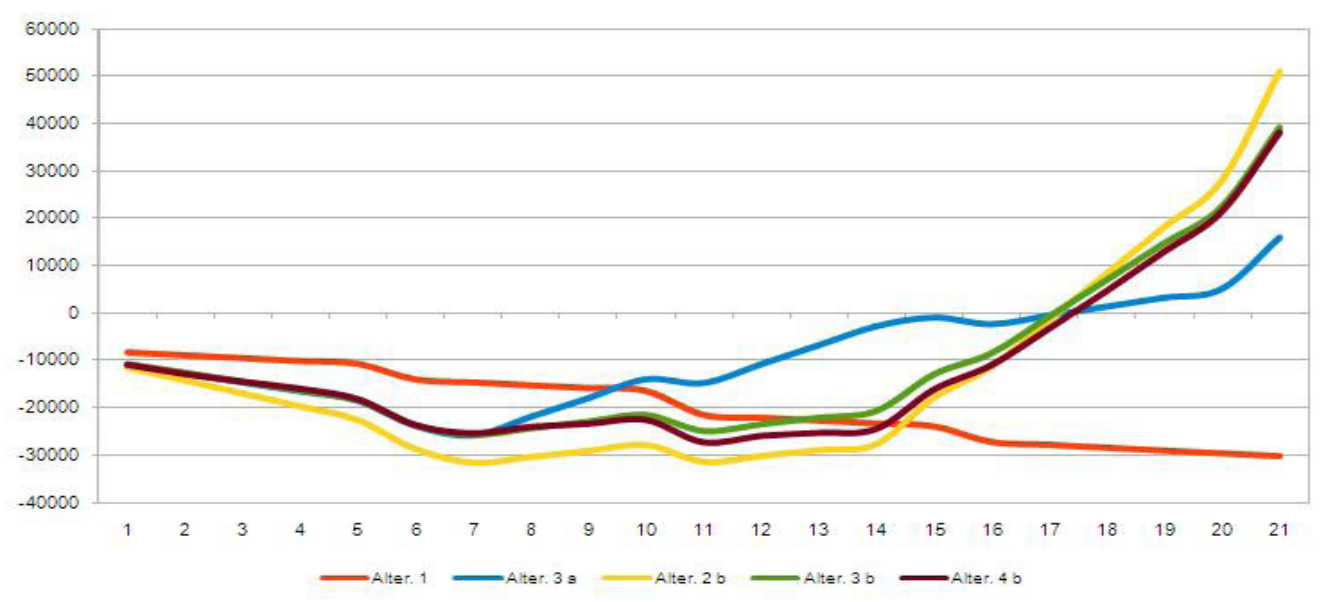

Figura 5. Comportamento anual acumulado da receita liquida até o $21^{\circ}$ ano (Resultado líquido $\left.\mathrm{R} \$ \cdot \mathrm{ha}^{-1}\right)$ das alternativas com TIR acima da TMA (3,72\%). a - manejo sem desbaste; b - manejo com desbaste seletivo de $70 \%$ das árvores no sétimo ano.

\section{Conclusões}

A pecuária extensiva, praticada nos moldes tradicionais não apresenta viabilidade econômica, apesar de o gado ser comercializado anualmente. Para este modelo, os custos de produção e a manutenção da infraestrutura superam as receitas obtidas.

Os sistemas silvipastoris e plantios florestais homogêneos, quando computados todos os investimentos, não apresentam rentabilidade superior à TMA.

Quando não se considera o valor de aquisição da terra, as alternativas que prevêem o desbaste apresentam TIR superior à TMA, exceto a alternativa com SSP de 500 árvores.ha ${ }^{-1}$, que não demonstra viabilidade econômica nas análises realizadas.

Os sistemas silvipastoris e os plantios homogêneos apresentam a possibilidade de incremento da renda com maior eficiência que a pecuária extensiva tradicional da região, e, consequentemente, apresentam maior tendência para oferecer a sustentabilidade socioeconômica.

A atividade silvipastoril fornece subsídios para a diversificação da renda do produtor. Entretanto, é necessário também que sejam implementadas ações que vislumbrem melhorias na qualidade do plantel bovino e no manejo das pastagens, oferecendo condições para que a renda de tais produtores seja incrementada. 


\section{Agradecimentos}

Os autores agradecem às instituições parceiras que direta ou indiretamente viabilizaram a realização deste trabalho: Unidades da Embrapa Florestas, Clima Temperado e Pecuária Sul, Universidade Federal do Paraná, Universidade Federal de Pelotas, Escola Agrotécnica Federal de Alegrete, Associação Gaúcha de Empresas Florestais, Secretaria de Agricultura de Alegrete, Emater/ RS-Ascar, Fundação Maronna e Estância Sá Brito.

\section{Referências}

ASSOCIAÇÃO GAÚCHA DE EMPRESAS FLORESTAIS (AGEFLOR). A economia da metade sul no limiar de uma nova era. 2005. Disponível em: $<$ http://www. celuloseonline. com.br/imagembank/Docs/DocBank/dc/dc027.pdf>. Acesso em: 28 dez. 2006.

BERGER, R. The brazilian fiscal incentive act's influence on reflorestation activity in São Paulo State. [S.1.: s.n.], 1979. Tese (Ph. D.) - Michigan State University, Michigan.

CASTILHOS, Z. M. S.; SAVIAN, J. F.; SANTOS, E. M.; AMARAL, H. R. B.; BELTRÃO, L. In: CONGRESSO FLORESTAL ESTADUAL DO RIO GRANDE DO SUL, 9., 2003, Nova Prata, RS. Floresta: função social: anais. Nova Prata: Prefeitura Municipal, 2003. 1 CD-ROM.

ILHA, A. S.; ALVES, F. D.; SARAVIA, L. H. B. Desigualdades regionais no Rio Grande do Sul: o caso da metade sul. 2006. Disponível em: <http://www.fee.rs.gov.br/sitefee/download/eeg/1/ mesa_3_ilha_alves_saravia.pdf $>$. Acesso em: 23/09/2006.

NABINGER, C. (Coord.). Alternativas sustentáveis do manejo de pastagens naturais: região da Campanha de RS. Porto Alegre: UFRGS, 2006. Disponível em: $<\mathrm{http}: / /$ wwwl.ufrgs.br/extensao/salaoextensao/mostra/vis acao mostra. asp?CodAcaoExtensao=8290>. Acesso em: 22 ago. 2007.

OLIVEIRA, E. B. de. SISEUCALIPTO-SISPINUS: Softwares para el manejo de plantaciones de Pinos y Eucaliptos. In: JORNADAS FORESTALES DE ENTRE RIOS, 17., 2002, Concórdia, Argentina. [Jornadas...]. [S.1.: s.n.], 2002. p. V1-V4. Papel.

OLIVEIRA, E.O.; PORFÍRIO-DA-SILVA, V.; MORAES, A.; RIBASKI, J. Utilização de softwares para o manejo de plantações florestais em sistemas silvipastoris. In: WORKSHOP [SOBRE] POTENCIAL DOS SISTEMAS SILVIPASTORIS PARA O DESENVOLVIMENTO DE MODELOS SUSTENTÁVEIS DE EXPLORAÇÃO PECUÁRIA, 1., 2006, Juiz de Fora. Palestras. Juiz de Fora: Embrapa Gado de Leite, 2006. 1 CD-ROM.
PILLAR, V. D.; BOLDRINI, I. I.; HASENACK, H.; JACQUES, A. V. A.; BOTH, R.; MÜLLER, S. C.; EGGERS, L.; FIDELIS, A.; SANTOS, M. M. G.; OLIVEIRA, J.M.; CERVEIRA, J.; BLANCO, C.; JONER, F.; CORDEIRO, J. L.; PINILLOS GALINDO, M. Workshop "Estado atual e desafios para a conservação dos campos". Porto Alegre: Universidade Federal do Rio Grande do Sul, 2006. 24 p. Disponível em $<$ http://ecoqua. ecologia.ufrgs.br.>. Acesso em: 22 ago. 2007.

RIBASKI, J.; MONTOYA VILCAHUAMAN, L. J.; RODIGHERI, H. R. Sistemas agroflorestais: aspectos ambientais e sócio-econômicos. Informe Agropecuário, Belo Horizonte, v. 22, n. 212, p. 61-67, set./out. 2001.

RIBASKI, J.; DEDECEK, R. A.; MATTEI, V. L.; FLORES, C. A.; VARGAS, A. F. C.; RIBASKI, S. A. G. Sistemas silvipastoris: estratégias para o desenvolvimento rural sustentável para a metade Sul do Estado do Rio Grande do Sul. Colombo: Embrapa Florestas, 2005. 8 p. (Embrapa Florestas. Comunicado técnico, 150).

RODRIGUEZ, L. C. E. Técnicas quantitativas para a gestão de florestas plantadas. Piracicaba, 1999. 120p. Tese (LivreDocência) - Escola Superior de Agricultura "Luiz de Queiroz", Universidade de São Paulo.

MIGUEL, L.A.; MIELITZ, C.G.A.; NABINGER, C.; WAQUIL, P.D.; SANGUINÉ, E.; SCHNEIDER, S. Caracterização socioeconômica e produtiva da bovinocultura de corte no estado do Rio Grande do Sul. Estudo \& Debate (Lajeado-RS), v. 14, p. 95-124, 2007.

SILVA, M. A. da. (Coord.).Diagnóstico de sistemas de pecuária de corte no Município de Alegrete-RS visando à preservação do ambiente. Porto Alegre: UFRGS, 2006. Disponível em: < http://www1.ufrgs.br/extensao/salaoextensao/ mostra/vis_acao_mostra.asp?CodAcaoExtensao $=8456>$. Acesso em: 22 ago. 2007.

SILVEIRA, R. L. V. A.; HIGASHI, E. N. Seja o doutor de seu eucalipto: Nutrição e adubação. Informações Agronômicas, n. 93. p. 1-23, 2001. (Arquivo do Agrônomo, n.12). Disponível em: <http://www.potafos.org/ppiweb/brazil.nsf/87cb8a98bf72572b 8525693e0053ea70/d5fbc829a2f54298832569f8004695c5/\$FILE/ Enc1-23-93.pdf>. Acesso em: 15 mar. 2009.

STAPE, J. L. Planejamento global e normalização de procedimentos operacionais da talhadia simples em Eucalyptus. Série Técnica IPEF, Piracicaba, v. 11, n. 30, 1997.

Recebido em 16 de junho de 2009 e aprovado em 29 de dezembro de 2009 
